\title{
Conversion of Thesis to Peer-Reviewed Publication
}

\author{
Dhaval Shukla ${ }^{1}$ Manjul Tripathi ${ }^{2}$ Bhagavatula Indira Devi ${ }^{1}$ \\ ${ }^{1}$ Department of Neurosurgery, National Institute of Mental Health \\ and Neurosciences, Bangalore, India \\ 2Department of Neurosurgery, Postgraduate Institute of Medical \\ Education and Research, Chandigarh, India \\ Indian J Neurosurg 2019;8:93-98
}

\begin{abstract}
Address for correspondence Dhaval Shukla, MCh, Department of Neurosurgery, National Institute of Mental Health and Neurosciences, Bangalore 560029, India (e-mail: neurodhaval@rediffmail.com).
\end{abstract}

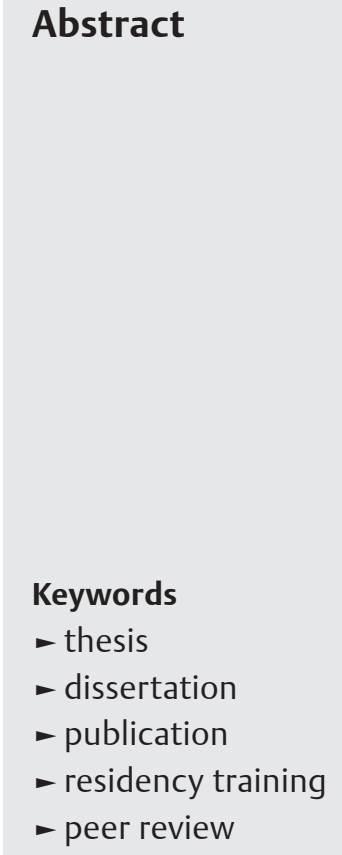

Abstract

\section{Introduction}

Writing a thesis or dissertation during a postgraduate medical or surgical training is a part of curriculum, which is considered a major component of training during residency. As per the guidelines laid by the Medical Council of India (MCI), evaluation of postgraduate medical education in any subject shall consist of thesis, besides theory, clinical or practical, and oral examinations. The thesis is a prerequisite for examinations as the MCI states that the thesis should be submitted at least 6 months before examination. The thesis should be evaluated by internal and external examiners, who should not be the examiners for theory and clinical examination. The candidate is permitted to appear in examination only after acceptance of the thesis by two examiners. The purpose of writing the thesis during residency is the development of a spirit of enquiry, besides exposing the candidate to the techniques of research, critical analysis, acquaintance with the latest advances in medical science, and the manner of identifying and consulting available literature. Every candidate should carry out work on an assigned research project under the guidance of a recognized postgraduate teacher, whose result shall be written up and submitted in the form of a thesis. ${ }^{1}$ However, the MCI does not mention about the quality of thesis. The recommendation of the Neurological Society of India (NSI) for uniform curriculum for neurosurgery residence mentions that the thesis should be of a good quality and worthy of publication in an indexed journal. ${ }^{2}$ In spite of such recommendations, the thesis is generally taken as a mere formality or a burden by both residents and faculty.

Our institute is a premier institute in the country for training in neurology, neurosurgery, and psychiatry. At our institute there are two different residency-training programs in neurosurgery: post Bachelor of Medicine, Bachelor of received

August 6, 2018

accepted

August 27, 2018

published online

August 27, 2019
Dol https://doi.org/

10.1055/s-0039-1694959

ISSN 2277-954X.
(C2019 Neurological Surgeons'

Society of India
License terms

(1) $\Theta \circledast$ 
Surgery (MBBS) for 5 years and post Master of Surgery (MS) for 3 years for award of MCh (Master of Chirurgiae) degree. An MBBS candidate is assigned a single topic whereas an MS candidate is assigned two topics. Since a post-MBBS student can pursue a longer follow-up, he/she is usually assigned a topic in basic science or a prospective study, whereas an MS candidate gets retrospective analysis. We aimed to analyze and find out the fate of theses of our residents, their outcome, and impact. We have also evaluated the reasons for not publishing the thesis as a peer-reviewed paper.

\section{Materials and Methods}

We obtained the list of neurosurgery residents, who graduated over a 10-year period from the 2004 to 2013. The thesis topics of these residents were obtained from the Library and Information Center of our institute. PubMed and Google Scholar were searched for the topics of thesis, names of residents, and their guides to find out whether any paper was published similar to topic of thesis. The faculties and residents were also personally contacted to find out the publication status of their thesis. The quality of thesis resulting in publication was judged by the average 5 -year impact factor of publishing journal. The impact factor of journal was obtained from the website www. citefactor.org. The factors contributing to publication were also analyzed. These included category of topics such as basic science or clinical and duration of course. The significance of difference between categorical variables was calculated using mid-P exact test. A questionnaire was sent to the student who did not publish their thesis to find out the reasons of not submitting for publication. A few faculties and current residents were interviewed to know their attitudes about thesis.

\section{Results}

Total 56 residents submitted 86 thesis topics. This included 28 post-MBBS candidate thesis and 58 post-MS thesis. There were 74 clinical topics, 9 basic science topics, and 3 animal studies. Most (94.9\%) of the post-MS thesis topics were clinical. Only $5.1 \%$ of MS topics were basic sciences in comparison to $22.2 \%$ of post MBBS topics $(p=0.017)$. None of the post-MS candidates conducted animal studies. Though most (66.7\%) of the post-MBBS thesis topics were clinical, $22.2 \%$ were basic science and $11.1 \%$ were animal studies. The rate of conversion to peer-reviewed publication was $32.5 \%$ (-Table 1). The conversion rate ranged from 9 to 56\% every year. There was decreasing trend of conversion to publication over 10 years ( $\boldsymbol{- F i g . 1}$ ). The conversion rate of thesis of post-MBBS candidate was $30 \%$ and post-MS candidate was $34.5 \%$; the difference was not significant $(p=0.71)$. The conversion rate of basic science thesis was $78 \%$ and clinical thesis was $27 \%$, the difference was significant $(p=0.005)$. None of the animal studies were published (-Table 1). One-half of the theses were published within 2 years of submission to institute ( - Fig. 2). Most (39.4\%) of the theses were published in journals with impact factor one to two, $21.4 \%$ in journals with impact factor more than two, and $17.8 \%$ in journals with impact factor less than one. Six (21.4\%) theses were published in journals with no recordable impact factor. Nearly $50 \%$ of the theses were published in either British Journal of Neurosurgery, Journal of Neurosurgery, or Neurology India.

Table 1 Type of thesis topics and conversion rate according to course

\begin{tabular}{|l|l|l|}
\hline $\begin{array}{l}\text { Type of course } \\
\text { Published/total (\%) }\end{array}$ & $\begin{array}{l}\text { Post-MS } \\
\text { Published/ } \\
\text { total (\%) }\end{array}$ & $\begin{array}{l}\text { Post-MBBS } \\
\text { Published/total } \\
(\%)\end{array}$ \\
\hline All topics 28/86 (32.5) & $209 / 59(34.5)$ & $8 / 27(30)$ \\
\hline Animal studies 0/3 (0) & $0 / 0(0)$ & $0 / 3(0)$ \\
\hline $\begin{array}{l}\text { Basic science studies } \\
7 / 9(78)\end{array}$ & $2 / 3(66.7)$ & $5 / 6(83.3)$ \\
\hline $\begin{array}{l}\text { Clinical studies 21/74 } \\
(28.4)\end{array}$ & $18 / 56(32.1)$ & $3 / 18(16.7)$ \\
\hline
\end{tabular}

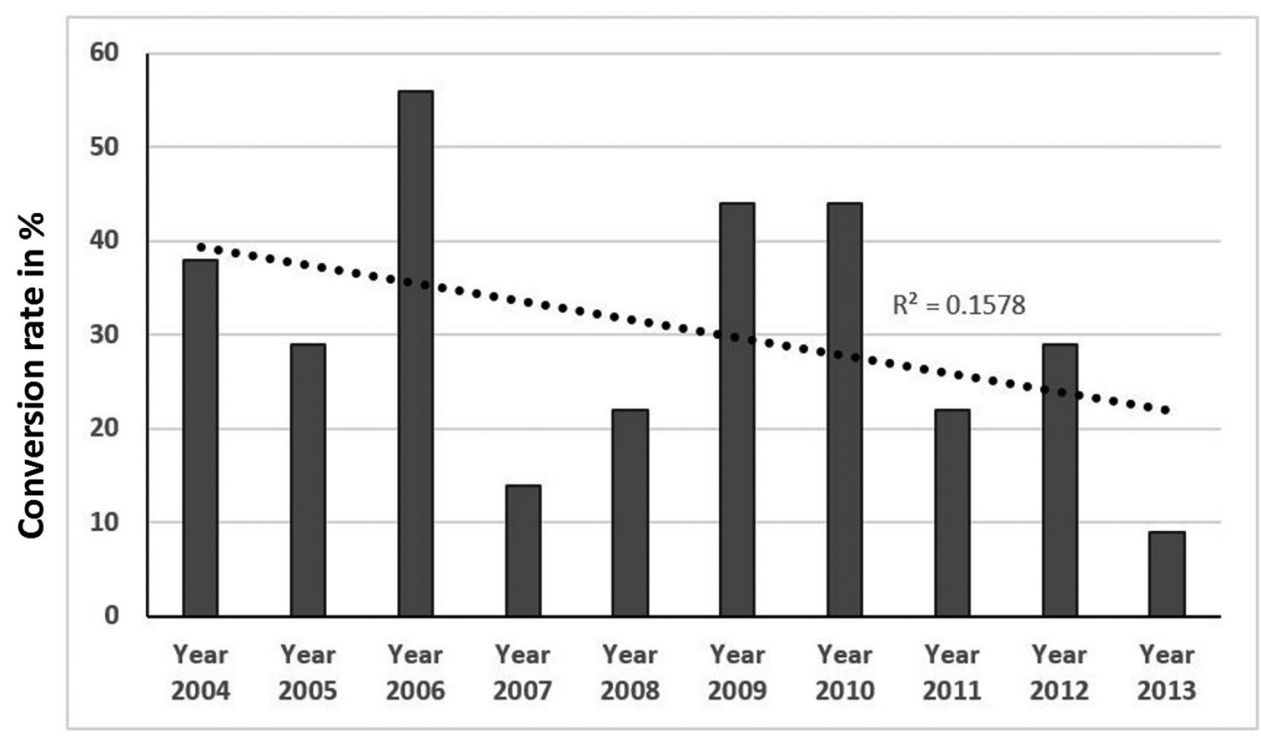

\section{Year of Submission}

Fig. 1 Trend in conversion of thesis to peer-reviewed paper over one decade. 


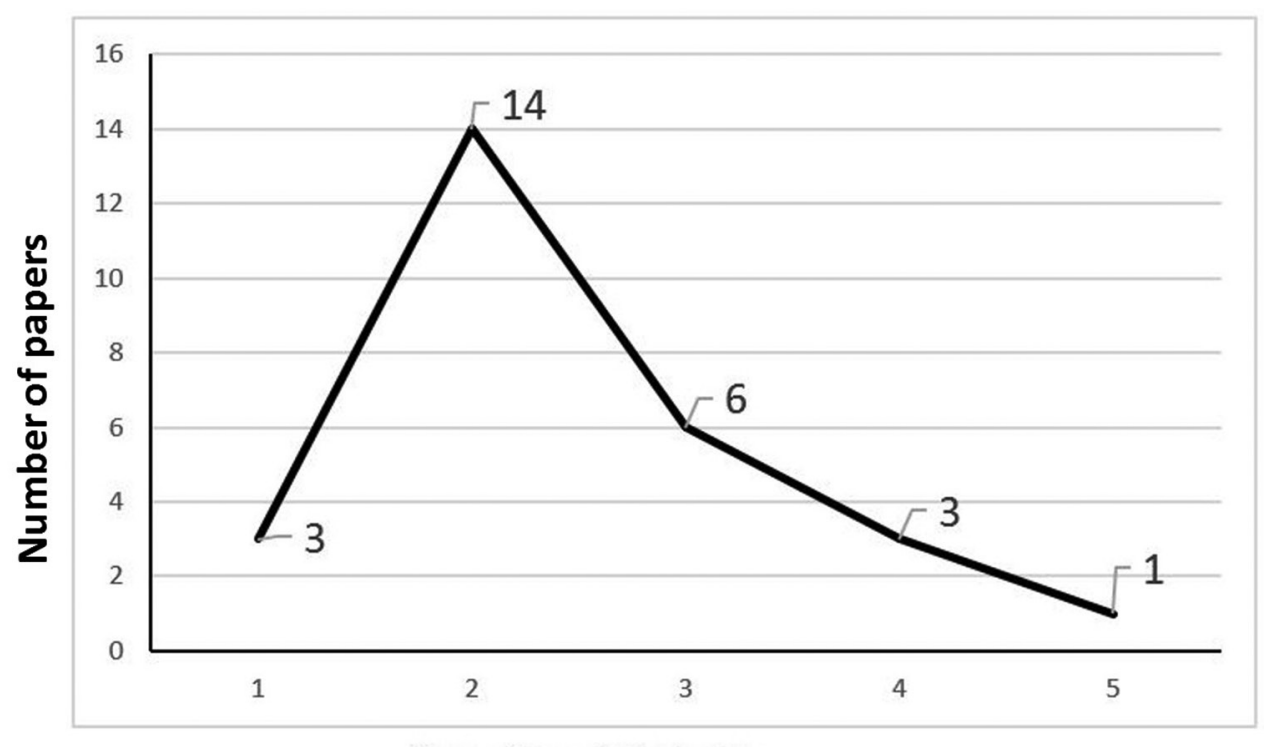

Years Since Submission

Fig. 2 Time to publication in years after submission of thesis.

The most common reasons for not publishing was a bad design of study, or deemed worthless for publication. The other reasons for not publishing thesis in decreasing order were following:

- Inadequate data, for example lack of follow-up, small sample size, etc.

- Rejected and did not try again

- Did not find need to publish

- No interest from student

- No interest from guide

- Negative/unexpected/inconclusive results

\section{Discussion}

The MCI mandates submission of thesis during postgraduate medical education program, that is, MS, but it does not specifically mention its necessity for super/subspecialization training, that is, MCh curriculum. Apart from thesis writing, there are no specific guidelines to monitor the quality of the dissertation. In India, most institutes offering MCh neurosurgery mandate submission of thesis. Though the NSI recommends that the thesis should be of a good quality, that is, worthy of publication in an indexed journal, whether it is practically followed or not is largely unknown and not monitored.

We did not encounter a study determining conversion of neurosurgery residents' thesis to paper. We aimed to determine the quality of thesis of our residents by conversion rate to peer-reviewed publication. The conversion rate in our institute is poor. The most common reason was "bad study design." This means that to begin with, the thesis was not designed with an aim to publish in most instances. The second most common reason was "inadequate data," for example lack of follow-up, small sample size, etc. As most of the theses are time bound, this factor cannot be eliminated. Before designing the thesis protocol, a "feasibility study" must be performed. As ethics committee clearance is mandatory for conducting study, sufficient time is spent before the recruitment of first subject. The studies aiming at long-term outcome cannot be given as resident's thesis. The other reasons were lack of interest from student or guide (faculty). If the rapport between both of them is not good, it is quite likely that a good research work may not translate into publication, which should be given due consideration at the time of selection of guide. At our institute, the student does not have right to select a guide. In such circumstances, the student is forced to carry on the designated subject irrespective of his/ her interest in topic or rapport with a faculty. The end result includes loss of valuable time, monetary and human resources, and a poor quality of data resulting in lack of publication. On the other hand, a good relationship between both leads to persuasion of publication as evidenced by publication of four theses even after 4 years of submission. An embarrassing reason for not publishing was "negative/unexpected/inconclusive results," which is fairly possible and still valuable information in research analysis. Both the student and faculty should be prepared for such circumstances. Even negative results should be published. None of the animal studies could translate into publication because of this reason.

A major limitation of our study is that we did not compare publication rates in other institutes of similar magnitude. We tried to contact faculties from other institutes but did not get a satisfactory data.

\section{Thesis Board: A Necessity in Reality}

To overcome these hurdles, there should be lean sigma approach to evaluate the bottlenecks and limiting factors in proper conduction of any dissertation. Every department should have a "thesis board" to regulate the efficient selection, conduction, and publication of the study ( - Fig. 3 ). The thesis board should always involve a statistician, experienced in scientific research from the very beginning. Efficient 


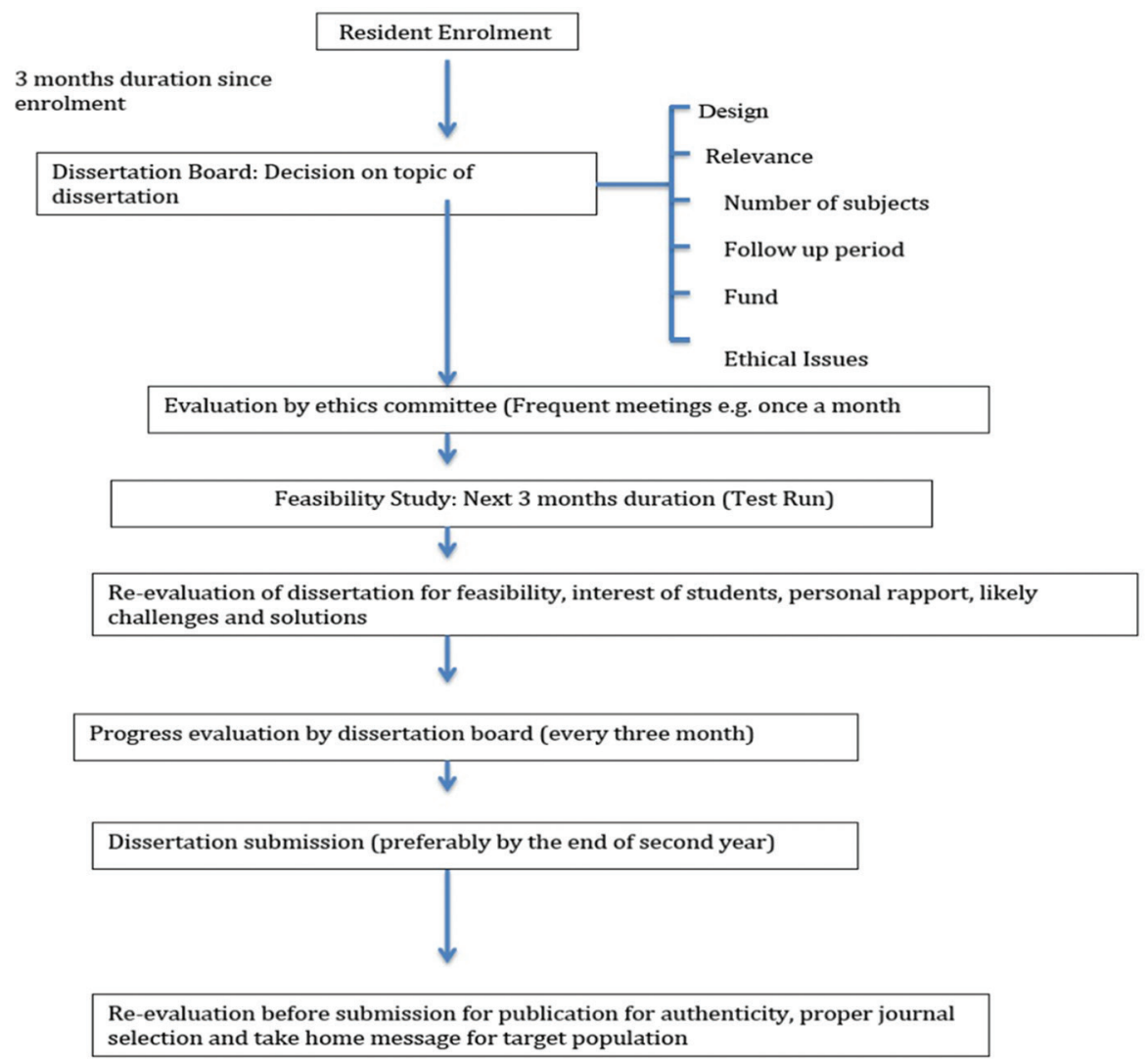

Fig. 3 Proposal of thesis board.

research is a team effort done in a limited frame of time. For a 3-year curriculum, a resident should be given a choice of dissertation topics at the end of initial 3 months. The dissertation board should evaluate this topic for its relevance, design, methodology, statistical requirements, likely expenditure, ethical concerns, duration of follow-up, and possible implications and contributions to the existing literature or practice. Ethics committee meetings should be more frequent (once or twice a month) to prevent the likely delay. Once approved, a feasibility run should be tested in 1-month duration. The dissertation board should reevaluate the study for interest of the candidate, practical problems (not identified earlier), rapport between candidate and guide, and likely challenges with solutions. The purpose of this exhaustive exercise is to identify the hurdles beforehand providing a lead time for the effective management. Once properly done, there should not be any change in the design and methodology of the study till its completion. Though a similar process is followed for a doctoral thesis leading to $\mathrm{PhD}$ degree, it is not followed for MCh thesis.

\section{Time since Submission to Publication}

Among the theses that got converted to publication, most were published within two years of submission. At our institute, majority of the residents continue as senior residents for another year after completion of their tenure. It is the most appropriate time to restructure the dissertation in a paper format. This is the golden year of opportunity to publish. It is very difficult to guide a resident, once they leave the institute. Apart from the geographical distances, professional commitments on the part of the resident and lack of direct monitoring further decrease the chances of publication. Publication of properly conducted thesis must always be done, irrespective of its results. It not only enriches the existing literature but also plants a seed for future research. Faculties should persuade the residents to submit their thesis for publication during this period. If it comes back for revision, it can be easily done in presence of resident. As basic science theses were more likely to get published, residents should be encouraged to take basic science topic.

\section{Attitudes of Residents}

For most residents, a dissertation is a burden, which has to be done. In medical slang, thesis and feces are same and it is better to pass them early. A survey of our 19 neurosurgery residents who are currently working for their thesis was conducted. The response rate was $84.2 \%$ ( - Fig. 4 ). The residents were asked two questions: "Should writing a thesis be a part of MCh neurosurgery residency?" and "If thesis is removed from residence program, what should be alternative?" Onethird residents felt that writing a thesis should not be part of neurosurgery residency. Fewer than half of them felt that thesis should be optional for residents who want to pursue research careers. When they were asked for the alternative to thesis, fewer than half of them felt that a full-length article 

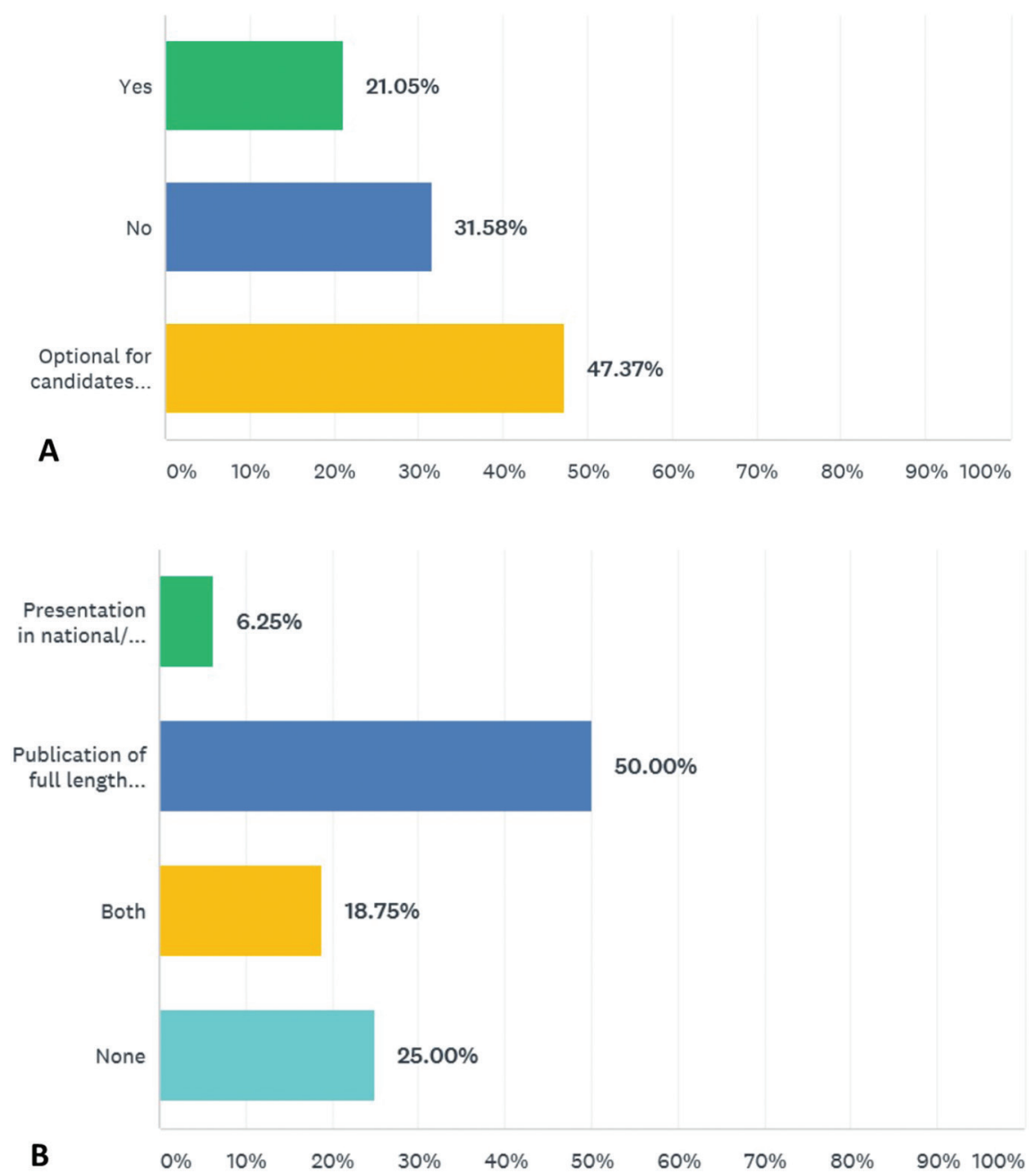

Fig. 4 Results of survey. (A) Response to question "Should writing a thesis be part of MCh neurosurgery residency?" (B) Response to question "If thesis is removed from residency program, what should be alternative?"

publication in peer-reviewed journal should be part of neurosurgery residency.

The residents were also interviewed informally, and they opined that the practical problems are insufficient time for the thesis, late decision regarding the topic, and lack of interest of the guide or candidate. They felt that the thesis topic should be from an ongoing research project of faculty so that it saves time of candidate for finding suitable topic, funds, and review of literature. They felt that a half of their final year is utilized for thesis, and they get much less time for reading for final exams.

\section{Differences between Thesis and Paper}

There are essential differences between thesis and publication. Theses are lengthy and exhaustive, whereas journal papers tend to be precise. Thesis has to be written using the university's framework for presentation, whereas a paper needs to address its likely readers and to adopt the target journal's specific format. The literature review portion of thesis has to be shrunk to introduction for publication purpose. A thesis contains a detailed description and/or statistical measurement and analysis. In view of word limitations in papers, one has to be accurate, brief, and precise while describing analysis, methodology, and techniques. Tables, charts, and other graphics are commonly used in thesis, but in journal papers, they tend to be used much more sparingly. The discussion of thesis is written in the past tense, whereas the discussion of paper needs to be more future-focused as the reader of the paper might take some of the ideas forward. Theses contain implications sections, but papers need to end with implications aiming at readership. Extensive referencing is an important part of any thesis, whereas in a journal paper, the referencing tends to be more selective, again due in part to the restriction in word count or number of references.

\section{Converting Thesis to Publication}

First step of publication is selection of appropriate journal. Most of the research literature is not published, as it is not submitted to a suitable journal. Finding an appropriate journal is the first step for publication. Two publishers "Elsevier (http://journalfinder.elsevier.com/)" and "Springer (https:// www.springer.com/gp/authors-editors/journal-author)" have author instruction sites where a suitable journal can be chosen by typing the research topic and abstract. Another site 
offering similar service is Edanz (http://www.edanzediting. com/journal_advisor). These websites use field of research specific vocabularies to guide to the right journal to publish articles. The analysis from these sites shows how to target relevant journal and its articles correlate with abstract. The analysis identifies the key words and concepts from content and analyzes published articles to find a set of target journals best matching publication goals. The second step is to identify the important difference between thesis and paper.

\section{Conclusion}

In a setup such as ours, dissertations are considered a liability and a token for appearance in the final examination. During the regular training, most students are busy in clinical activities and hardly get any time for research activities. It definitely affects the quality of research, which should ideally be a full-time activity. The candidate sums up the work in a proposed duration of time and often with a predetermined outcome. With the gradual passage of times, academic institutes have realized their responsibility to contribute in scientific publications, which not only helps in their recognition but also provides them credibility on the academic front. If not properly monitored, these confounding factors devaluate the quality and importance of a dissertation. It is a moral responsibility of the guide to reevaluate the dissertation for its authenticity to prevent the corruption of world literature. Publication is not a goal for thesis, but a milestone in thesis. Thesis is intended to inculcate a research aptitude among residents irrespective of their future plans. However, it is desirable that emphasis on publication should be given besides writing thesis. Such publications can be done in a short period of time and carry more significance in long duration.

\section{References}

1 The Postgraduate Medical Education Regulations. 2000 [Internet]. Available at: http://www.mciindia.org/RulesandRegulations/PGMedicalEducationRegulations2000.aspx. Accessed July 24, 2015

2 Uniform Curriculum for MCh and DNB Neurosurgery. 2014 [Internet]. Available at: http://www.neurosocietyindia.com/ NewLaunch/Download/UNIFORM CURRCULUM FOR MCh AND DNB NEUROSURGERY.pdf. Accessed July 24, 2015 